\title{
Anticarcinogenic effects of water extract of sporoderm-broken spores of Ganoderma lucidum on colorectal cancer in vitro and in vivo
}

\author{
KUN NA, KANG LI, TINGTING SANG, KAIKAI WU, YING WANG and XINGYA WANG \\ College of Pharmaceutical Sciences, Zhejiang Chinese Medical University, Hangzhou, Zhejiang 310053, P.R. China
}

Received January 14, 2017; Accepted March 13, 2017

DOI: $10.3892 /$ ijo.2017.3939

\begin{abstract}
Ganoderma lucidum (G. lucidum) polysaccharides (GLPs) have been used as traditional Chinese medicine for cancer prevention for many years. However, the mechanism by which GLP exerts its chemopreventive activities remains elusive. In addition, it is unclear whether sporoderm-broken spores of G. lucidum water extract (BSGLWE), which contains mainly GLPs, has anticancer effects on colorectal cancer. The present study investigated the anticancer effects and potential mechanisms of BSGLWE on colorectal cancer in vivo and in vitro. Our results showed that BSGLWE significantly inhibited colorectal cancer HCT116 cell viability in a time- and dose-dependent manner. Flow cytometry analysis indicated that BSGLWE disrupted cell cycle progression at G2/M phase via downregulation of cyclin B1 and cyclin A2, and upregulation of P21 at mRNA levels. Moreover, BSGLWE induced apoptosis by decreasing Bcl-2 and survivin at mRNA levels, and reduced $\mathrm{Bcl}-2$, PARP, pro-caspase-3 and pro-caspase-9 at protein levels. Furthermore, BSGLWE suppressed tumor growth in vivo by regulating the expression of genes and proteins associated with cell cycle and apoptosis, which was further confirmed by a reduction of Ki67, PCNA, and Bcl-2 expression as determined by immunohistochemistry staining. NSAID activated gene-1 (NAG-1), a pro-apoptotic gene, was significantly upregulated in vivo and in vitro upon BSGLWE treatment at both mRNA and protein levels. In addition, the relative amounts of secreted NAG-1 in cell culture medium or serum of nude mice were all upregulated upon BSGLWE
\end{abstract}

Correspondence to: Dr Xingya Wang, College of Pharmaceutical Sciences, Zhejiang Chinese Medical University, 548 Binwen Road, Hangzhou, Zhejiang 310053, P.R. China

E-mail: xywang@zcmu.edu.cn

Abbreviations: NAG-1, non-steroidal anti-inflammatory drugactivated gene-1; GDF15, growth differentiation factor 15; BSGLWE, sporoderm-broken spores of Ganoderma lucidum water extracts; GLP, Ganoderma lucidum polysaccharides

Key words: Ganoderma lucidum, sporoderm-broken spores, colorectal cancer, apoptosis, cell cycle, proliferation, non-steroidal anti-inflammatory drug-activated gene-1 treatments, suggesting a role of NAG-1 in BSGLWE-induced anticolorectal cancer activity. This is the first study to show that BSGLWE inhibits colorectal cancer carcinogenesis through regulating genes responsible for cell proliferation, cell cycle and apoptosis cascades. These findings indicate that BSGLWE possesses chemopreventive potential in colorectal cancer which may serve as a promising anticancer agent for clinical applications.

\section{Introduction}

Colorectal cancer is one of the most common malignant tumors and the fourth leading cause of cancer-related death around the world, with roughly 1.4 million new cases and nearly 700,000 deaths per year (1). According to research prediction, colon cancer cases will increase to 2.2 million, and the number of deaths may reach 1.1 million by 2030 (1). To date, the pathogenesis of colorectal cancer is not completely elucidated. Many factors including age, family heredity, diet, inflammation, and obesity may all contribute to the development and progression of colorectal cancer (2). Besides surgery, the current means of treating colorectal cancer mainly are radiotherapy, chemotherapy and immunotherapy, which are associated with unwanted side effects and leading to decreased life quality of patients. Therefore, the development of safe and effective novel anticolorectal cancer agents from nature is urgently needed.

In recent years, natural products have been widely studied by researchers for their remarkable effects and less side effect in the prevention and treatment of colorectal cancer. For example, xanthones extracted from Garcinia mengostana inhibited colon cancer tumorigenesis both in vivo and in vitro (3). Resveratrol, mainly found in grapes, has been shown to prevent the development and progression of colorectal tumors by downregulating Kras expression (4). Besides results from laboratory studies, a number of clinical trials also demonstrated that nature compounds along or as supplements have potential in treating colorectal cancer $(5,6)$. These studies suggest that nature compounds may serve as promising anticancer agents in the prevention and treatment of colorectal cancer.

Ganoderma lucidum (G. lucidum), also known as Lingzhi or Reshi, is a traditional Chinese medicine that has been used in East Asian countries for promoting health and longevity for 
over thousands of years (7). In the past few decades, many researchers studied the biological function and examined the responsible active components of G. lucidum. Many studies reported that G. lucidum has numerous pharmacological effects, including immunomodulatory, antiallergenic, anti-oxidative, cardiovascular protective, antidiabetic, and antitumor effects $(8,9)$. Modern uses of G. lucidum include treatment of coronary heart diseases, arteriosclerosis, hepatitis, arthritis, nephritis, asthma, bronchitis and cancer (9). A diverse group of active compounds including polysaccharide, triterpenoids, alkaloids, fatty acids, lactones, steroids and others were identified and isolated from G. lucidum (10). In recent years, much attention has been focused on G. lucidum polysaccharide (GLP), a structurally diverse class of biological macromolecules, which contribute to numerous pharmacological effects of G. lucidum. In particular, the antitumor effects of GLP have attracted much attention.

A substantial number of studies demonstrated that GLP inhibited carcinogenesis in many types of cancer, including liver (11), breast $(12,13)$, leukemia (14), ovarian (15), lung $(16,17)$, and colorectal cancer (18). Early studies suggest that the anti-carcinogenic effects of GLP may be due to its immunomodulatory activity (19). In addition, the study of anticancer mechanisms of GLP was mainly restricted to GLP extracted from fruiting body of G. lucidum or mycelia cultivated in liquid culture medium. Recently, with the advance in sporoderm-breaking technology, much attention has been paid to chemical components of the sporoderm-broken spores of G. lucidum (BSGL) and their versatile biological activities. One study found that the spores of G. lucidum contain a large amount of bioactive substances and have a higher bioactivity than the fruiting bodies of G. lucidum (20). Another study showed the amount of polysaccharide of sporoderm-broken spores is 1.7 times that of unbroken ones (21). Research has suggested that the growth inhibition rate of BSGL on HepG2 cells was significantly higher than unbroken ones (22). These studies suggest that BSGL may serve as promising anticancer agent for cancer chemoprevention and therapy.

In this study, we examined the effects and mechanism of BSGL water extract (BSGLWE), which mainly contains GLP, on colorectal cancer development and progression in vitro and in vivo. To our knowledge, this is the first study to examine the effects of BSGLWE on colon cancer. Our data suggest that BSGLWE is effective against colorectal cancer development through regulating cell cycle, apoptosis, proliferation and necrosis.

\section{Materials and methods}

Materials. Hoechst 33342 was purchased from Invitrogen (Carlsbad, CA, USA). [3-(4, 5-dimethylthia-zol-2-yl)-2, 5-diphenyltetrazolium bromide] (MTT) was obtained from HXBIO (Hangzhou, China). FITC Annexin V Apoptosis Detection Kit I and propidium iodide (PI)/RNase staining kit were purchased from BD Pharmingen (San Diego, CA, USA). Polyclonal $\beta$-actin (\#4967s), PARP (\#9542), Bcl-2 (\#2876s) antibodies; monoclonal caspase-3 (\#9665), caspase-9 (\#9508), Foxo3a (75D8) (\#2497p) and horseradish peroxidase-conjugated secondary antibody were obtained from Cell Signaling Technology (Danvers, MA, USA). The NAG-1 polyclonal rabbit antibody was generated in this laboratory as described before (23). Human GDF15/NAG-1 ELISA kit (NAG-1 also known as growth differentiated factor 15 GDF15) was from R\&D Systems (Minneapolis, MN, USA). RNA extraction kit was from Aidlab Biotech (Beijing, China). The iScript cDNA synthesis kit and SYBR master mix were purchased from Bio-Rad (Hercules, CA, USA). The bicinchoninic acid (BCA) assay kit was from Pierce (Rockford, IL, USA). The Western Lightening ${ }^{\mathrm{TM}}$ Plus-ECL Enhanced chemiluminescence Substrate assay kit was from Perkin-Elmer (Waltham, MA, USA).

Water extract preparation of BSGLWE. The powder of sporodum-broken spores of Ganoderma lucidum was purchased from Taian Zhenxin LLC (Shandong, China). The polysaccharides from the powder of sporoderm-broken spores of G. lucidum were extracted by hot water extraction method. Briefly, $5 \mathrm{~g}$ of sporoderm-broken spores of G. lucidum powder was placed in $100 \mathrm{ml}$ of double distilled water, and stirred (300 rpm) at $70^{\circ} \mathrm{C}$ for $12 \mathrm{~h}$. The solution was centrifuged at $4000 \mathrm{rpm}$ for $15 \mathrm{~min}$ to remove insoluble materials. The supernatant was concentrated and freeze-dried using H051 freeze dryer, ScanVac (LaboGene, Lynge, Denmark). For subsequent cell culture experiment, the powder of sporodermbroken spores of G. lucidum water extract (BSGLWE) was dissolved in Dulbecco's modified Eagle's medium (DMEM) from Gibco (Gaithersburg, ML, USA) with 10\% fetal bovine serum (FBS) as stock solution of $10 \mathrm{mg} / \mathrm{ml}$, and then passed through $0.22-\mu \mathrm{m}$ filter and diluted to required concentrations.

Cell culture. Human colorectal cancer cell line HCT116 was purchased from the American Type Culture Collection (ATCC, VA, USA). Cells were maintained in a humidified atmosphere with $5 \% \mathrm{CO}_{2}$ at $37^{\circ} \mathrm{C}$ in DMEM supplemented with $10 \%$ FBS. For experiments, cells were seeded in serum-containing medium and at $60-80 \%$ confluence, cells were treated with BSGLWE at different concentrations and treated for certain time adjusted by each experiment.

Cell viability assay. Cell viability was assessed by MTT assay. Briefly, cells $\left(1 \times 10^{4}\right)$ were seeded in 96-well plates and incubated in DMEM medium containing 10\% FBS until cells reach $50 \%$ confluence. HCT116 cells were than treated with $0,1.25,2.5,5$, and $7.5 \mathrm{mg} / \mathrm{ml}$ BSGLWE for 24,48 and $72 \mathrm{~h}$. Then MTT solution $(5 \mathrm{mg} / \mathrm{ml})$ was added and incubated for an additional $4 \mathrm{~h}$. After incubation, supernatants were removed and the remaining water-insoluble formazan crystals were dissolved in $150 \mu \mathrm{l}$ DMSO for 10 min with gentle shacking. The optical density was measured at $490 \mathrm{~nm}$ using a multi-well plate reader (Bio-Tek Instruments Inc., Winooski, VT, USA). The percentage of viability was calculated and compared with that of the control cells without BSGLWE treatment. The $50 \%$ inhibitory concentration $\left(\mathrm{IC}_{50}\right)$ of BSGLWE was calculated as the 50\% decrease in the optical density compared to untreated controls.

Hoechst 33342 staining. Nuclear fragmentation was examined by Hoechst 33342 . Briefly, HCT116 cells treated with BSGLWE at $0,1.25,2.5,5,7.5 \mathrm{mg} / \mathrm{ml}$ for $24 \mathrm{~h}$, and cells were stained with Hoechst $33342(10 \mu \mathrm{g} / \mathrm{ml})$ for $15 \mathrm{~min}$ at room 
temperature. Cells were observed using a fluorescence microscope (Olympus).

Flow cytometric analysis of cell cycle and apoptosis. Flow cytometric assay was used for cell cycle and apoptosis assays. Briefly, for cell cycle determination, equal numbers of HCT116 cells $\left(2 \times 10^{5}\right)$ were seeded in 6-well plate per well and incubated with different concentration of $\operatorname{BSGLWE}(0,5,7.5 \mathrm{mg} / \mathrm{ml})$ for 36 h. The cells were washed with PBS and then collected, and fixed in $70 \%$ ice cold ethanol, and storage at $-20^{\circ} \mathrm{C}$ for at least $2 \mathrm{~h}$. Cells were then washed with PBS twice, and centrifuged for $10 \mathrm{~min}$ at $1200 \mathrm{rpm}$ and aspirate the supernatant, and resuspended cells in $0.5 \mathrm{ml}$ of PI/RNase staining buffer (BD Pharmingen) for $15 \mathrm{~min}$ at room temperature, and DNA content was immediately analyzed using Guava Easycyte HT flow cytometry system (Guava Technologies, Merck KGaA, Darmstadt, Germany), and quantified using ModFit 3.2 software (Verity Software House, Topsham, ME, USA). For apoptosis examination, approximately $2 \times 10^{5}$ cells per well were also seeded in 6-well plates and treated with $0,1.25,2.5$, 5 , and $7.5 \mathrm{mg} / \mathrm{ml} \mathrm{BSGLWE}$ for 24, 36 and $48 \mathrm{~h}$. Cells were then collected and stained with Annexin V-FITC/PI at room temperature in the dark and then analyzed by flow cytometer (Guava Technologies, Merck KGaA). The percentage of Annexin $\mathrm{V}^{-} / \mathrm{PI}^{+}$(necrosis), Annexin $\mathrm{V}^{+} / \mathrm{PI}^{-}$(early apoptosis) and Annexin $\mathrm{V}^{+} / \mathrm{PI}^{+}$(late apoptosis) cells were calculated according to manufacturer's instruction (BD Pharmingen). Samples were subsequently analyzed by flow cytometer (Merck Millipore Corp., Darmstadt, Germany).

In vivo tumor xenograft study. All the experimental procedures were conducted following the Guide for the Use and Care of Laboratory Animals of the National Institutes of Health. This study was approved by the Committee on the Ethics of Animal Experiments of Zhejiang Chinese medical University (Permit Number: SYXK 2012-0002). All procedures in this protocol are in compliance with the Animal Welfare Act Regulations. Four-week-old male BALB/C nude mice were kept in Specific Pathogen Free (SPF) environment. After 2 weeks of adaptation, mice were randomly divided by weight. HCT116 cells were injected subcutaneously (s.c.) into the left flank of each nude mouse $\left(5 \times 10^{6}\right.$ cells in $200 \mu \mathrm{l}$ PBS). The mice were randomized into treatment and control groups: control group (saline, $n=18)$, low dose $(150 \mathrm{mg} / \mathrm{kg}, \mathrm{n}=18)$, high dose $(300 \mathrm{mg} / \mathrm{kg}, \mathrm{n}=18), 5-\mathrm{FU}$ treatment $(20 \mathrm{mg} / \mathrm{kg}, \mathrm{n}=8)$.

The day after injection of tumor cells, the high and low dose group mice were treated with BSGLWE intraperitoneally per day, while the control group mice were injected saline per day, and 5-FU was given every two days through intraperitoneal administration. However, 5-FU administration was reduced to every four days after a dramatic weight loss at 2 weeks after HCT116 cell injection. Tumor volume and body weights were measured twice a week and palpable tumors were measured in two dimensions (length and width) using a digital vernier caliper $(0.01 \mathrm{~mm})$. Tumor volume was calculated using the equation $\mathrm{V}\left(\mathrm{mm}^{3}\right)=$ length $\mathrm{x}$ width ${ }^{2} / 2$. Six weeks after injection, all mice were sacrificed. At necropsy, the xenograft tumors were carefully excised and weighed. Half of all tumors were fixed in $10 \%$ neutral formalin and processed for hematoxylin and eosin (H\&E) and immunohistochemical staining. The rest of the tumor tissue was snap-frozen in liquid nitrogen and stored at $-80^{\circ} \mathrm{C}$ for subsequent analysis. Terminal blood was collected by cardiac puncture for the analysis of the circulating level of NAG-1/GDF15 secreted from HCT116 xenografts.

RNA exaction and quantitative real-time PCR. Total RNA was extracted from HCT116 cells and HCT116 xenograft tumors by RNA extraction kit as described by Aidlab Biotech. Both the quantity and quality of total RNA were analyzed by the Agilent Bioanalyzer 2100 system. Total RNA $(1 \mu \mathrm{g})$ was reverse transcribed with an iScript cDNA synthesis kit (Bio-Rad). Real-time PCR was performed to determine the expression of listed genes using SYBR PCR master mix (Bio-Rad) on CFX96 Real-time PCR system (Bio-Rad). $\beta$-actin was used as the reference gene for all samples. The PCR conditions consisted of 40 cycles, with 5 sec denaturation at $95^{\circ} \mathrm{C}, 30 \mathrm{sec}$ annealing at $60^{\circ} \mathrm{C}$ and $5 \mathrm{sec}$ extension at $65^{\circ} \mathrm{C}$. The relative expression of mRNA for each sample was calculated as follows: $\Delta \mathrm{Ct}=\mathrm{Ct}$ (sample) $-\mathrm{Ct}(\beta$-actin $), \Delta \Delta \mathrm{Ct}$ (sample) $=\Delta \mathrm{Ct}$ (sample) $-\Delta \mathrm{Ct}$ (calibrator). The fold change in mRNA was calculated through relative quantification $\left(2^{-\Delta \Delta \mathrm{Ct}}\right)$. Table I shows the primer sequences of all the primers used in this experiment.

Western blotting. Total protein from HCT116 cells and xenograft tumors were extracted using standard methods and protein concentrations were determined by BCA protein assay kit. A total of $40 \mu \mathrm{g}$ of protein were loaded onto a 10 or $12 \%$ SDS-polyacrylamide gel and electrophoresed at $100 \mathrm{~V}$ for $2 \mathrm{~h}$. Separated proteins were transferred onto a PVDF (polyvinylidene difluoride) membrane at $100 \mathrm{~V}$ for $2 \mathrm{~h}$ on ice. After transfer, membranes were blocked with $5 \%$ nonfat dry milk in 1X TBST (Tris-buffered saline with Tween; $50 \mathrm{mmol} / \mathrm{l}$ of Tris, $\mathrm{pH} 7.5,150 \mathrm{mmol} / \mathrm{l}$ of $\mathrm{NaCl}, 0.1 \%$ Tween-20) at room temperature for $1 \mathrm{~h}$. The membrane was probed with NAG-1, Bcl-2, PARP, Foxo3a or $\beta$-actin primary antibodies overnight at $4^{\circ} \mathrm{C}$ and then secondary antibody at RT for $1 \mathrm{~h}$ according to manufacturer's instructions. The membrane was stripped using Restore Western Blot Stripping Buffer according to manufacturer's instruction. After stripping, the membrane was re-probed for $\beta$-actin as a loading control. The signals were detected using the Western Lightning Plus ECL-enhanced chemiluminescence substrate according to manufacturer's instruction. ImageJ 1.41 software (Bethesda, MD, USA) was used for the calculation of the optical density.

Enzyme-linked immune sobert assay. HCT116 cells ( $2 \times 10^{5}$ cells/well) were plated in 6-well plate and incubated at $37^{\circ} \mathrm{C}$. After treatment with BSGLWE for $48 \mathrm{~h}$, cell culture medium was collected for ELISA analysis. Total protein concentrations were determined by BCA assay in cell lysates. The quantification of GDF15/NAG-1 protein was determined using the Quantikine GDF15/NAG-1 ELISA kit (R\&D). The concentration of NAG-1 in cell culture medium and serum of nude mice were determined by comparing their optical density to standard curve. Data were presented as normalized by protein concentration in cell culture medium or by tumor weights in serum of nude mice. 

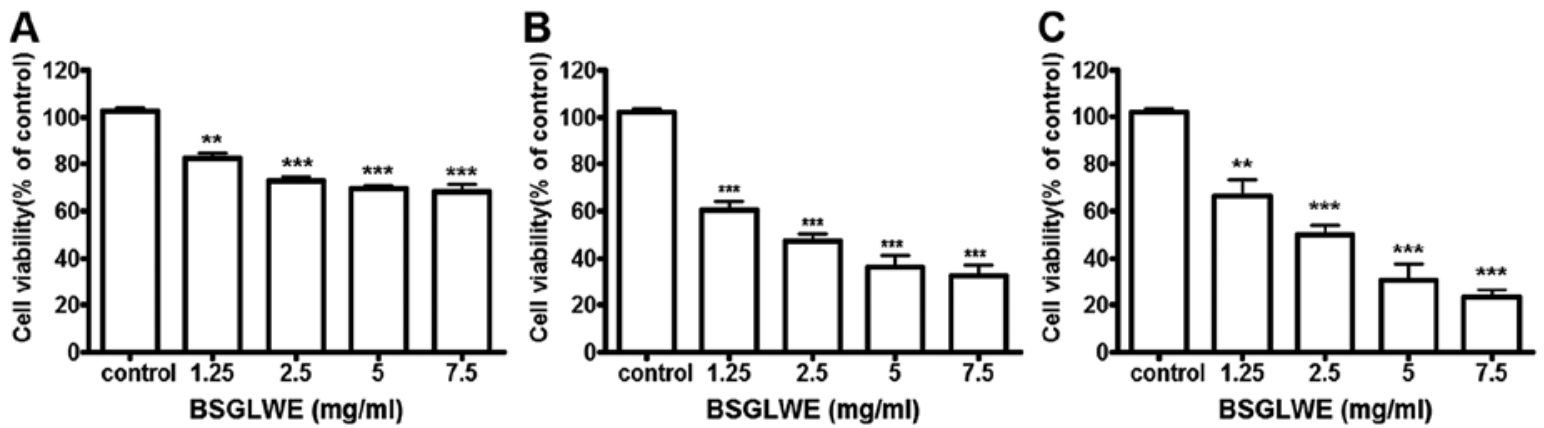

Figure 1. BSGLWE $(0,1.25,2.5,5,7.5 \mathrm{mg} / \mathrm{ml})$ induces HCT116 cell viability in treatment for 24 (A), 48 (B) and $72 \mathrm{~h}$ (C). Cell viability was examined using MTT assay. Data shown are the means of 3 independent experiments. Data are presented as mean $\pm \mathrm{SE}$. ${ }^{*} \mathrm{p}<0.05 ;{ }^{* *} \mathrm{p}<0.01 ;{ }^{* * *} \mathrm{p}<0.001$, as compared with control group.
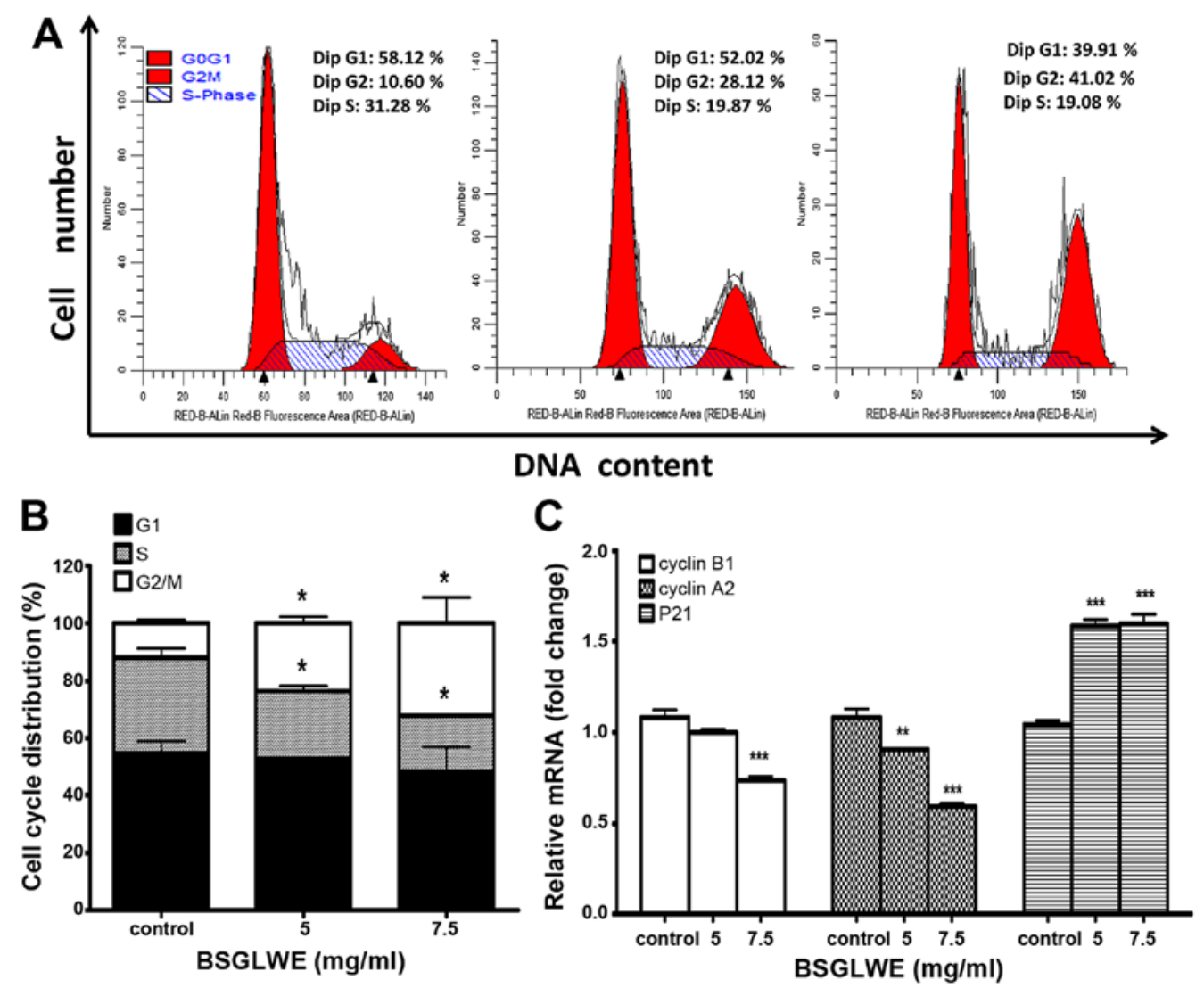

Figure 2. BSGLWE induces cell cycle arrest at G2/M phase in HCT116 cells. (A) HCT116 cells were treated with BSGLWE at 0,5, 7.5 mg/ml for 36 h. Cell cycle was analyzed by flow cytometry. (B) Quantified histograms demonstrated the effect of BSGLWE on HCT116 cell cycle distribution. (C) The expression of the G2/M phase-related gene, cyclin B1, cyclin A2 and P21 were examined by qRT-PCR in HCT116 cells. Data are presented as the mean \pm SE of three independent experiments. ${ }^{*} \mathrm{p}<0.05 ;{ }^{* *} \mathrm{p}<0.01 ;{ }^{* * *} \mathrm{p}<0.001$, as compared with control group.

Immunohistochemistry. Formalin-fixed tumor tissues were embedded in paraffin and cut into $4-\mu \mathrm{m}$ sections. The sections were then stained with $\mathrm{H} \& \mathrm{E}$ for pathological evaluation. The rest of the paraffin blocks were cut into $4-\mu \mathrm{m}$ sections. The sections were deparaffinized using citric acid buffer $(\mathrm{pH} 6.0)$ and incubated for $8 \mathrm{~min}$ at $100^{\circ} \mathrm{C}$. The slides were treated with $3 \%$ hydrogen peroxide to block endogenous peroxidase activity and then incubated with $1 \%$ bovine serum albumin (BSA) for $25 \mathrm{~min}$. Next, the slides were incubated overnight at $4^{\circ} \mathrm{C}$ with anti-human primary antibodies: Bcl-2 (GB12008, 1/100 diluted in 1\% BSA), Ki67 (GB13030-2, 1/1000 diluted in $1 \%$ BSA), PCNA (GB11010, 1/500 diluted in 1\% BSA).
All primary antibodies were obtained from Wuhan Goodbio Technology Co., Ltd. (Wuhan, China). The slides were then incubated with $5 \mu \mathrm{g} / \mathrm{ml}$ biotinylated anti-goat IgG secondary antibody (Dako, Carpinteria, CA, USA) for $50 \mathrm{~min}$ at room temperature. After washing, slides were stained with 3,3-diaminobenzidine (DAB) (Dako), washed and counterstained with hematoxylin, dehydrated, and then mounted with a coverslip. All images were captured using an inverted fluorescence microscope (Nikon, Japan).

Statistical analysis. GraphPad Prism 5 (GraphPad Software, Inc., La Jolla, CA, USA) was used for all statistical analysis. 
Table I. Primers used in qRT-PCR.

\begin{tabular}{lll}
\hline Primers & \multicolumn{1}{c}{ Forward } & \multicolumn{1}{c}{ Reverse } \\
\hline$\beta$-actin & CTGGAACGGTGAAGGTGACA & AAGGAACTTCCTTGAACAATGCA \\
Bcl- 2 & AAGAGCAGACGGATGGAAAAAGG & GGGCAAAGAAATGCAAGTGAATG \\
Surviving & GCATGGGTGCCCCGCGT & TGGCTCCGGCCAGAGGCCTCAA \\
NAG- 1 & CTCCAGATTCCGAGAGTTGC & AGAGATACGCAGGTGCAGGT \\
NF-kB & ATGGCTTCTATGAGGCTGAG & GTTGTTGTTGGTCTGGATGC \\
TNF- $\alpha$ & AGAGGGAGAGAAGCAACTACA & GGGTCAGTATGTGAGAGGAAGA \\
c-FOS & GTGGCTTCCCTTGATCTGACTG & AACAGGAAGTCATCAAAGGGCT \\
FOXO3 & GCAAACCCTCTCGGACTCTC & CCCACGTTCAAACCAACAAC \\
Cyclin A2 & ATGTCACCGTTCCTCCTTG & GGGCATCTTCACGCTCTATT \\
Cyclin B1 & GCCAATAAGGAGGGAGCAGT & ACCTACACCCAGCAGAAACC \\
Cyclin D1 & GTGGCCTCTAAGATGAAGGAGA & GGAAGTGTTCAATGAAATCGTG \\
P16 & ACCAGAGGCAGTAACCATGC & TGATCTAAGTTTCCCGAGGTTT \\
P21 & TTAGCAGCGGAACAAGGAGT 1 CGTTAGTGCCAGGAAAGACA \\
WEE1 & TGTGGTGGTGTGCTGCTTAT & TTCAAAGGGAGGGTATGTCTG \\
E2F 1 & CCAACTCCCTCTACCCTTGA & GTCTCCCTCCCTCACTTTCC \\
RB1 & ACTCTCACCTCCCATGTTGC & TGCACTCCTGTTCTGACCTC \\
HIF-1 $\alpha$ & GGGCAATCAATGGATGAAAG & AGTAATTCTTCACCCTGCAG \\
FADD & ACGCTTCGGAGGTAGATG & CCTGGTACAAGAGGTTCA \\
TRAF2 & CACCGGTACTGCTCCTTCTG & TGAACACAGGCAGCACAGTT \\
Caspase-8 & CCAGAGACTCCAGGAAAAGAGA & GATAGAGCATGACCCTGTAGGC \\
\hline
\end{tabular}

Data are expressed as mean \pm standard error (SE). Differences between groups were examined for statistical significance by t-test. Two-sided P-values were calculated, and a value of $\mathrm{P}<0.05$ was considered to be statistically significant.

\section{Results}

BSGLWE inhibits cell viability in a dose-and time-dependent manner. To explore the growth inhibitory potential of BSGLWE against colon cancer, HCT116 cells were treated with BSGLWE at various concentrations for 24, 48 and $72 \mathrm{~h}$. MTT assays revealed that cell viability was significantly decreased upon BSGLWE treatment in a time- and dosedependent manner in HCT116 cells (Fig. 1). Specifically, at $24 \mathrm{~h}$, with the increase of BSGLWE from 0 to $7.5 \mathrm{mg} / \mathrm{ml}$, cell viability decreased from 100 to $68.36 \%$ in HCT116 cells $(\mathrm{p}<0.001$, Fig. 1A). This inhibitory effect was further enhanced upon 48 and $72 \mathrm{~h}$ of treatments $(\mathrm{p}<0.001$, Fig. $1 \mathrm{~B}$ and C). Using highest concentration as example, HCT116 cells treated with $7.5 \mathrm{mg} / \mathrm{ml}$ BSGLWE reduced cell proliferation to $68.36 \pm 3.02$, $32.66 \pm 4.66$ and $23.59 \pm 2.81 \%$ at 24,48 and $72 \mathrm{~h}$, respectively $(\mathrm{p}<0.001)$, suggesting that longer incubation with BSGLWE could markedly increase cytotoxicity of BSGLWE to HCT116 cells. The $\mathrm{IC}_{50}$ was determined to be $2.24 \mathrm{mg} / \mathrm{ml}$ and $2.40 \mathrm{mg} /$ $\mathrm{ml}$ at 48 and $72 \mathrm{~h}$, respectively (data not shown).

BSGLWE induces cell cycle arrest at G2/M phase. In order to investigate the anticancer mechanism of BSGLWE in HCT116 cells, we determined the effects of BSGLWE on cell cycle distribution by flow cytometry analysis. As shown in Fig. 2A and $2 \mathrm{~B}$, the ratio of HCT116 cells in G0/G1 phase slightly decreased upon BSGLWE treatments at non-significant level, while the ratio of cell population in $\mathrm{S}$ phase significantly decreased $(\mathrm{p}<0.05)$. Compared to control cells, BSGLWE significantly increased percentage of $\mathrm{G} 2 / \mathrm{M}$ phase from $12.00 \pm 1.09$ to $23.75 \pm 2.21 \%$ and to $32.20 \pm 8.85 \%$ upon 5 and $7.5 \mathrm{mg} / \mathrm{ml}$ of treatments, respectively ( $<<0.05$, Fig. $2 \mathrm{~B}$ ).

To confirm this result, the expression levels of $\mathrm{G} 2 / \mathrm{M}$ checkpoint regulators such as cyclin $\mathrm{B} 1$ and cyclin $\mathrm{A} 2$ were examined. As shown in Fig. 2C, the expression of cyclin B1 and cyclin A2 at mRNA levels were significantly downregulated by BSGLWE treatments $(\mathrm{p}<0.001)$. In addition, the mRNA level of P21, a cell cycle arresting protein, was significantly upregulated ( $<<0.001$, Fig. 2C). Taken together, our results indicate that BSGLWE may inhibit HCT116 cell proliferation through regulating key genes involved in arresting cell cycle progression at $\mathrm{G} 2 / \mathrm{M}$ phase.

BSGLWE induces apoptosis in vitro. To further elucidate the mechanism of cell death induced by BSGLWE in HCT116 cells, Hoechst 33342 staining was carried out. The changes in the cell nuclei were observed under the fluorescence microscope. As shown in Fig. 3A, the nuclei of HCT116 cells had blue fragmentation compared with control cells as indicated by distinct features of condensation, coagulation, and fragmentation of the nuclear chromatin, as well as typical apoptotic bodies as highlighted in circles (Fig. 3A). We also used flow cytometry analysis to further study the ability of BSGLWE in inducing apoptosis in HCT116 cells. As shown in Fig. 3B, we observed that the amount of Annexin $\mathrm{V}^{+} / \mathrm{PI}^{-}$(early apoptosis) and Annexin $\mathrm{V}^{+} / \mathrm{PI}^{+}$(late apoptosis) stained cells were both increased significantly upon BSGLWE $(1.25,2.5,5$, 

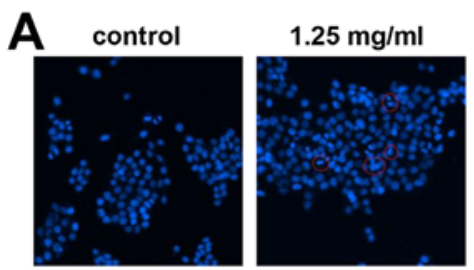

B
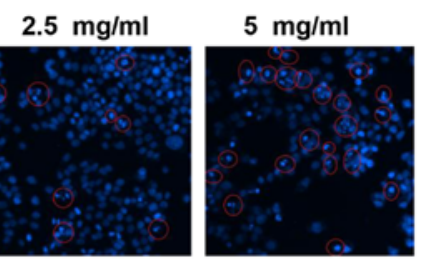

$2.5 \mathrm{mg} / \mathrm{ml}$

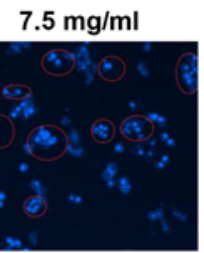

$5 \mathrm{mg} / \mathrm{ml} \quad 7.5 \mathrm{mg} / \mathrm{ml}$
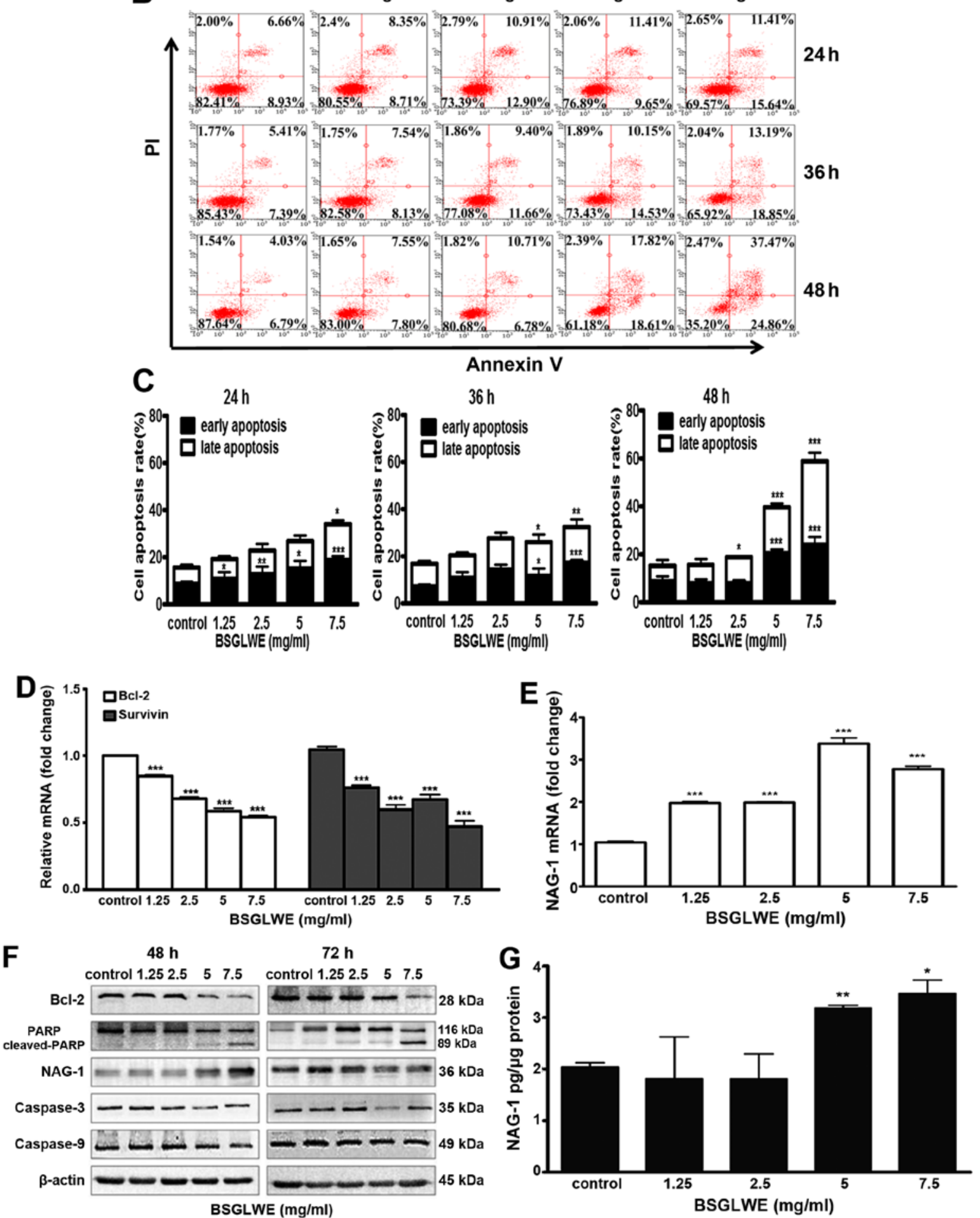

Figure 3. BSGLWE induces apoptosis in HCT116 cells. (A) Cells were treated with different concentration of BSGLWE for 24 h. Hoechst 33342 staining was used to analyze the apoptotic cells. (B) BSGLWE (0, 1.25, 2.5, 5, $7.5 \mathrm{mg} / \mathrm{ml})$ induced apoptosis in HCT116 at 24,36 and $48 \mathrm{~h}$. Apoptosis was quantified by Annexin V/FITC flow cytometry. (C) The apoptosis ratio of HCT116 cells increased in dose-/time-dependent manner with BSGLWE treatment. (D and E) Quantification of the mRNA levels of apoptosis-related genes after treatment with BSGLWE. (F) The expression of apoptosis-associated proteins, Bcl-2, PARP, NAG-1, caspase-3 and caspase- 9 were assessed by western blotting. $\beta$-actin used as an internal control. (G) Concentration of NAG- 1 in cell culture medium was examined by ELISA assay, data presented was normalized by concentration of protein lysates. Data are present as mean \pm SE of three independent experiments, ${ }^{*} \mathrm{p}<0.05 ;{ }^{* *} \mathrm{p}<0.01 ;{ }^{* * * *} \mathrm{p}<0.001$, as compared with control group. 
and $7.5 \mathrm{mg} / \mathrm{ml}$ ) treatments dose-dependently, and in a timedependent manner at 24, 36 and $48 \mathrm{~h}(\mathrm{p}<0.001)$. The rate of early and late apoptotic cells were quantified and depicted in Fig. 3C.

The relative mRNA expression levels of different regulatory genes involved in apoptosis were then determined by qRT-PCR. Treatment with different concentrations of BSGLWE $(1.25-7.5 \mathrm{mg} / \mathrm{ml})$ upregulated the expression of survivin and reduced the expression of Bcl-2 ( $\mathrm{p}<0.001$, Fig. 3D). However, the mRNA level of bax was not changed upon BSGLWE treatment (data not shown). Additionally, the expression of Bcl-2 at protein level was also reduced by BSGLWE at dose-dependent manner upon 48 and $72 \mathrm{~h}$ of treatments as determined by western blotting (Fig. 3F). In particular, higher concentrations of BSGLWE (5 and $7.5 \mathrm{mg} / \mathrm{ml}$ ) seemed to have more effects then lower doses in inducing apoptosis in HCT116 cells.

In addition, BSGLWE treatment downregulated the procaspase-3 and pro-caspase-9 expression at protein levels as determined by western blotting in a time-dependent manner (Fig. 3F), suggesting caspase activation. We also found total PARP was cleaved and cleaved-PARP was significantly increased by BSGLWE in HCT116 cells at 48 and $72 \mathrm{~h}$ (Fig. 3F).

Nonsteroidal anti-inflammatory drug-activated gene (NAG-1) or growth differentiated factor 15 (GDF15), a proapoptotic gene, is a divergent member of the transforming growth factor $\beta$ (TGF- $\beta$ ) superfamily (24). Previous studies have reported that NAG-1 plays an important role in inhibiting tumor growth (25-28). It has been well studied that many natural products demonstrate their anticancer effects through upregulating NAG-1 expression (24). Our previous studies and results from many other laboratories suggest that NAG-1 plays a key role in inhibiting cancer cell proliferation through inducing apoptosis $(24,25)$. For example, Piyanuch et al demonstrated that berberine-induced apoptosis of colon cancer cells was through upregulating the expression of NAG-1 (29). Therefore, we also determined effects of BSGLWE on NAG-1 induction in HCT116 cells. As shown in Fig. 3E and F, BSGLWE significantly induced the expression of NAG-1 at both mRNA and protein levels $(\mathrm{p}<0.001)$. Since NAG-1 is a secreted protein, we used ELISA to quantify NAG-1 concentration in cell culture medium. After normalized by total protein concentration in cell lysates, our results showed a positive correlation between the secretion of NAG-1 in cell culture medium and the concentration of BSGLWE at 5 and $7.5 \mathrm{mg} / \mathrm{ml}$ (p<0.01) (Fig. 3G). However, low doses (1.25 and $2.5 \mathrm{mg} / \mathrm{ml})$ of BSGLWE seemed not potent enough to induce NAG-1 secretion in HCT116 cells. Taken together, these results suggest that BSGLWE significantly induced apoptosis in colorectal cancer HCT116 cells through regulating key molecules involved in apoptosis cascades. NAG-1 may play an important role in BSGLWEinduced apoptosis and growth inhibition in HCT116 cells.

BSGLWE reduces tumor growth in colon cancer xenograft in nude mice. To evaluate the antitumor effects of BSGLWE in vivo, we examined the effects of low dose and high dose of BSGLWE $(150 \mathrm{mg} / \mathrm{kg}$ vs. $300 \mathrm{mg} / \mathrm{kg})$ by oral gavage on tumor growth in a mouse tumor xenograft model. 5-FU was used as positive control. Fig. 4A shows two representative photograph of the average size of the tumor volume from each group, which indicates reduced tumor volume in BSGLWE treated group compared with control group. Both lower dose and higher dose of BSGLWE inhibited HCT116 xenograft tumor growth and decreased the final tumor volume in dose-dependent manner by 23.8 and $47.8 \%(\mathrm{P}<0.05)$, respectively (Fig. 4C). The final tumor weights at necropsy of the two doses were all significantly lower than control group ( $<<0.05$, Fig. 4B). Final tumor weights of the four groups were $2.22 \pm 0.11 \mathrm{~g}$ (control), $1.27 \pm 0.19 \mathrm{~g}(150 \mathrm{mg} / \mathrm{kg}), 1.00 \pm 0.21 \mathrm{~g}(300 \mathrm{mg} / \mathrm{kg})$ and $1.28 \pm 0.23 \mathrm{~g} \mathrm{(5-FU)} \mathrm{(p<0.05)} \mathrm{(Fig.} \mathrm{4B).}$

Compared with the control group, the body weight of BSGLWE treated mice did not change significantly, while the body weights of 5-FU treated group decreased significantly two weeks after injection (Fig. 4D). Therefore, we had to reduce the frequency of 5-FU administration to nude mice. In addition, no other adverse effects such as skin ulcerations or toxic death were observed in BSGLWE groups. This result suggests that BSGLWE may have less toxicity to mice compared to 5-FU.

In order to study how BSGLWE inhibited tumor development in vivo, we examined the expression of related genes and proteins that regulate the cell cycle, proliferation, and apoptosis by qRT-PCR and western blotting in xenograft tumor samples. As shown in Fig. 4E, we found the relative expression of cell cycle inhibitors, P16 and the retinoblastoma gene (RB1) at mRNA levels, were significantly increased in $300 \mathrm{mg} / \mathrm{kg}$ BSGLWE treated tumors compared to controls, while the expression of P21, also a cell cycle inhibitor, was increased but at non-significant level. In addition, WEE1, E2F1 mRNAs were significantly decreased in HCT116 xenograft tumors upon BSGLWE treatments $(\mathrm{p}<0.05)$ (Fig. 4E). It was reported that WEE1 is upregulated in several types of cancer, and inhibition of WEE1 in tumor could cause mitotic catastrophe in glioblastoma cancer (30-32). E2F1 transcription factor plays a positive role in G1/S phase progression (33). Moreover, both mRNA and protein levels (as depicted in histograph) of FOXO3a, a cycle progression inhibitor, were significantly upregulated in xenograft tumors by BSGLWE treatment in a dose-dependent manner (Fig. 4E and H). The high expression of FOXO3a not only causes cell cycle stagnation in the mitotic phase, but also make the cells more susceptible to injury and apoptosis (34). We also examined the expression of cyclin D1 and cyclin B1, and found they were reduced upon BSGLWE treatment, but at non-significant levels (Fig. 4E). These results indicate that BSGLWE may inhibit HCT116 xenograft tumor development through inhibiting cell cycle progression.

In addition, we examined the expression of apoptosis related genes such as Bcl-2, TNF- $\alpha$, NF- $\mathrm{B}, \mathrm{HIF}-1 \alpha$, FADD, TRAF2, caspase- 8 and c-FOS by qRT-PCR. As shown in Fig. 4F, BSGLWE significantly reduced the expression of anti-apoptosis genes including Bcl-2, NF- $\kappa \mathrm{B}$, and c-FOS in xenograft tumors compared to controls in a dose-dependent manner $(\mathrm{p}<0.05)$ (Fig. 4F), while the pro-apoptotic gene TNF- $\alpha$, caspase-8, TRAF2, and FADD were significantly induced by BSGLWE. We also found PARP expression was downregulated slightly as determined by western blotting ( $\mathrm{p}>0.05$, Fig. 4G).

To further examine whether NAG-1 may also play a role in the antitumor effects of BSGLWE in vivo, we examined the expression of NAG-1 in xenograft tumors and serum samples. Interestingly, we found that NAG-1 protein expression was significantly upregulated in a dose-dependent manner in 

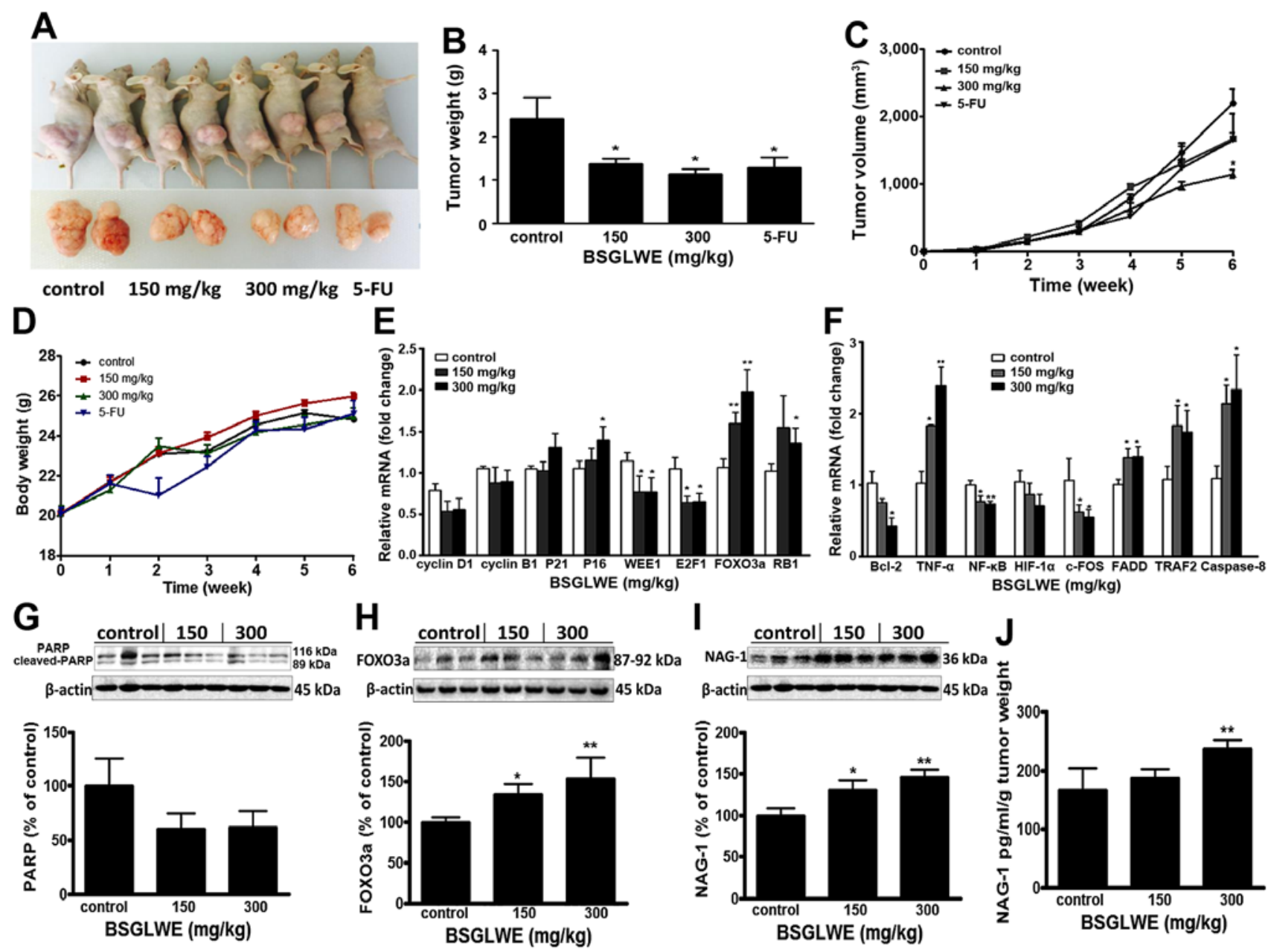

Figure 4. BSGLWE inhibits tumor growth in HCT116 xenograft nude mice. (A) Representative image of the average tumor volume from control, $150 \mathrm{mg} / \mathrm{ml}$, $300 \mathrm{mg} / \mathrm{ml}$ and 5-FU groups. (B) Average final tumor weight of each group. (C) Growth curve of tumor volume in nude mice. (D) Effect of BSGLWE and 5-FU treatment on body weight of nude mice. (E) Expression of cell cycle regulatory genes in xenograft tumors as determined by qRT-PCR. (F) Quantification of the mRNA levels of apoptosis-associated genes treatment with different doses of BSGLWE in xenograft tumors as determined by qRT-PCR. (G-I). Expression of PARP, NAG-1, and Foxo3a in xenograft tumor at protein levels as determined by western blotting. Densitometry analysis is presented; and $\beta$-actin was used as internal control. (J) Concentration of NAG-1 in serum of nude mice was detected by ELISA assay, data were normalized by tumor weights. Data are presented as mean $\pm \mathrm{SE}$ of three independent experiments, ${ }^{*} \mathrm{p}<0.05 ;{ }^{* *} \mathrm{p}<0.01$, as compared with control group.

HCT116 xenograft tumors upon BSGLWE treatment ( $<<0.01$, Fig. 4I). We then measured the concentration of NAG-1 in serum of tumor-bearing mice by ELISA, and found that after normalized by tumor weights, the relative concentration of NAG-1 protein was increased upon BSGLWE treatment with a significant upregulation by $300 \mathrm{mg} / \mathrm{kg}$ treatment (p<0.01, Fig. 4J).

Immunohistochemistry was done to determine expression of PCNA and Ki67, which are important cell nuclear proliferation markers. The expression of PCNA and Ki67 were markedly decreased in BSGLWE treatment groups dose-dependently compared with control group (Fig. 5A), indicating that the BSGLWE effectively inhibit proliferation of colon tumor cells in vivo. In addition, we found anti-apoptotic marker Bcl-2 was markedly reduced in tumor sections of BSGLWE treatment groups (Fig. 5B). Taken together, these data suggest that the inhibitory effects of BSGLWE on colorectal tumorigenesis in xenograft model may be through regulating key molecules involved in inhibition of cell proliferation, increase of cell cycle arrest and induction of apoptosis.
BSGLWE induces necrosis in nude mouse xenograft tumors. $\mathrm{H} \& \mathrm{E}$ was used to observe the pathological changes in xenograft tumors after different treatments. Compared with control group, the tumor necrosis area increased in the xenograft tumors treated with BSGLWE. The pictures indicate that BSGLWE obviously induced necrosis in a dose-dependent manner in the xenograft tumors compared with control group (Fig. 6A and B). The zoomed-in image from $300 \mathrm{mg} / \mathrm{kg}$ treated (Fig. 6A upper right image), necrotic area was mainly characterized by large blurred, massive, unstructured red-stained material, mixed with blue-stained nucleus fragments in the tumor tissue as compared with dark purple stained living cells in non-necrotic area (Fig. 6C and D).

\section{Discussion}

In recent years, the interest in natural compounds for prevention and treatment of cancer has increased. Various classes of anticancer agents derived from plants including alkaloids, saponins, polysaccharides, terpenoids and flavonoids have been extensively studied in laboratories 

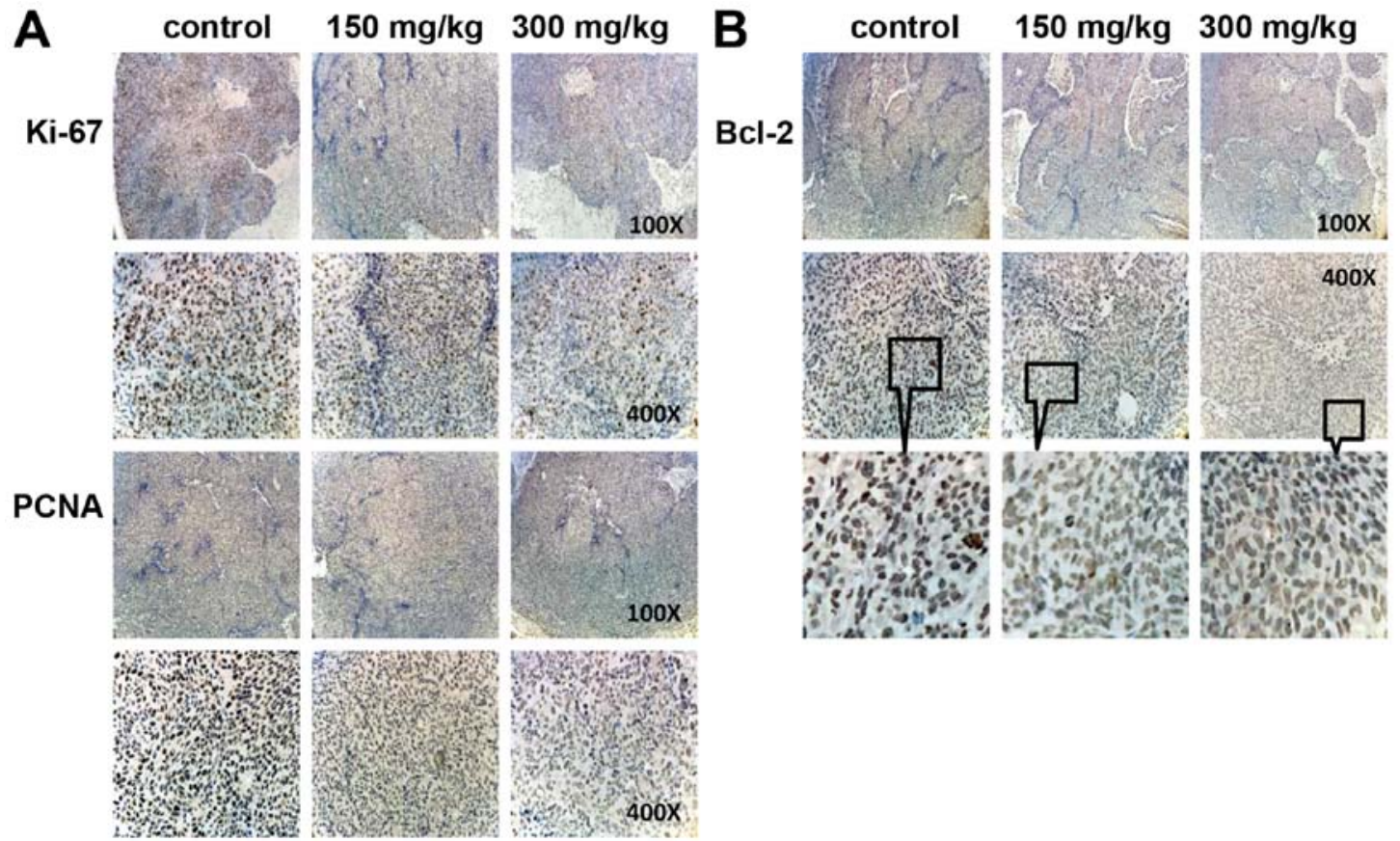

Figure 5. BSGLWE reduces cell proliferation and apoptosis markers as determined by immunohistochemical staining, including Ki67 and PCNA (A); and Bcl-2 (B). Compared with control group, proliferation markers Ki67 and PCNA were significantly reduced, as well as apoptosis markers Bcl-2 significantly decreased. Sections were observed under a microscope (x100, x400, and x400 digital zoom-in).

and clinical investigations. The anticancer activities of the water-soluble extract of G. lucidum, which mainly contains GLP, has also been recognized. Available studies suggest that the anticancer mechanism of GLP may include immunomodulation $(35,36)$, suppression of tumor angiogenesis (16), inhibition of cancer cell invasion and metastasis (37), inhibition of tumor cell proliferation and induction of tumor cell apoptosis (38), as well as reduction of the anticancer drug resistance (39). However, GLP is a mixture of peptidoglycan, glucose, heteropolysaccharide and other polysaccharides $(8,10)$. Due to the complex structure of GLP and the limitation of separation and analysis, the composition of GLP has not yet been fully identified. Bioactive GLP has been isolated from the fruiting bodies of G. lucidum, from the mycelia cultivated in liquid culture medium, and from the spores of G.lucidum (19). Recently, studies found that the BSGL possesses more bioactive GLP than fruiting bodies of G. lucidum or mycelia and also showed more potent ability in inhibiting cancer cell growth than unbroken spores (20-22).

In this study, we demonstrate that BSGLWE (mainly contains GLP) is potent in inhibiting colorectal cancer cell growth and tumor development through causing cell cycle arrest, inhibiting cell proliferation and inducing apoptosis both in vitro and in vivo. NAG-1 gene, which plays an important role in inhibiting carcinogenesis in many cancers, may be a key target of BSGLWE for its chemopreventive activity in colorectal cancer. To our knowledge, this is the first study to examine the anticarcinogenic effects and mechanisms exerted by BSGLWE in colorectal cancer, and first to show NAG-1 could be induced by BSGLWE in cancer cells.

Cancer is caused by the imbalance of cell proliferation and cell death, and is considered as a genetic disease that occurs with increased genetic instability involved in regulation of many cellular processes (13). These processes include proliferation, apoptosis, angiogenesis, cell cycle progression and invasion (40). Cell cycle disorder is one of the main contributors to carcinogenesis $(41,42)$. The normal cells operate in the exact chronological order through G1-S-G2-M phase under the precise control by cell cycle molecular network system $(41,42)$. Deregulation of cell cycle would cause imbalance between cell proliferation and apoptosis, which may eventually lead to cancer. Our results suggest that BSGLWE could arrest cell cycle at $\mathrm{G} 2 / \mathrm{M}$ phase as determined by flow cytometry in HCT116 cells. BSGLWE significantly decreased mRNA levels of cyclin A2, cyclin B1 and increased the expression of P21 in HCT116 cells. Both downregulation of cyclin A2 and cyclin B1 induced cell cycle arrest at G2/M phase (43). P21 has a wide range of kinase inhibitory activity inhibiting the activity of various cyclin-CDK complexes that cause primarily G1 arrest $(44,45)$. However, some studies suggest that upon upregulation, P21 also plays an important role in G2/M arrest (46). These results suggest that BSGLWE may cause HCT116 cell G2/M phase arrest through upregulating P21 and downregulating cyclin A1 and cyclin B2. Consistent with our study, Zhao et al found that G. lucidum whole extract induced cell cycle arrest at G2/M phase in ovarian cancer cells (47). Wang et al found that GLP extracted from fruiting body of G. lucidum could inhibit breast cancer cell proliferation through G2/M phase cell cycle arrest (48). However, at present, no study examined effects of GLP extracted from sporoderm-broken spores on cell cycle arrest.

We also found that the expression of WEE1 and E2F were significantly downregulated while the expression of P16, FOXO3a and RB1 were significantly upregulated in the xenograft tumors of the nude mice upon BSGLWE treatment. P16 can compete with cyclin D1 binding to CDK6 or CDK4 and 


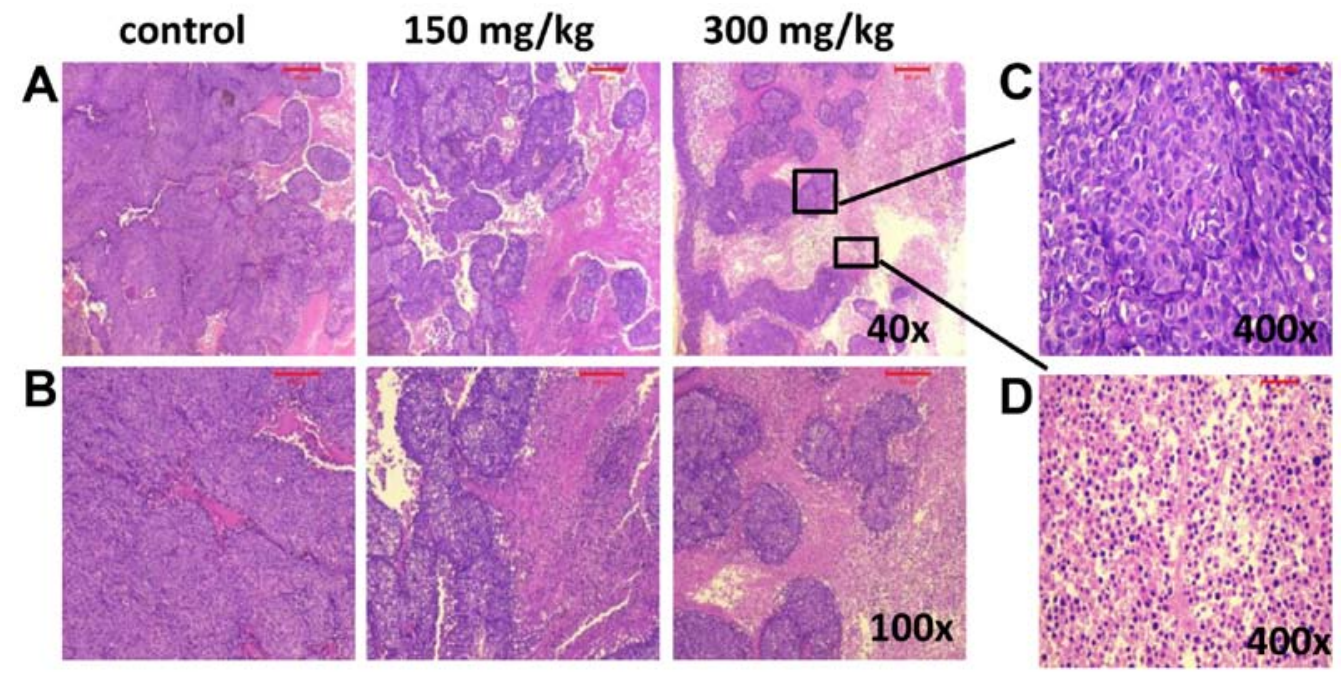

Figure 6. BSGLWE induces necrosis in xenograft tumors. Histological analysis of tumor tissue samples from each treatment group. Tumor tissues were stained with hematoxylin and eosin (H\&E). Images captured at x40 (A), x100 (B). Representative image from $300 \mathrm{mg} / \mathrm{kg}$ treatment group showing living cells $(\mathrm{C}, \mathrm{x} 400)$ and necrotic cells $(\mathrm{D}, \mathrm{x} 400)$.

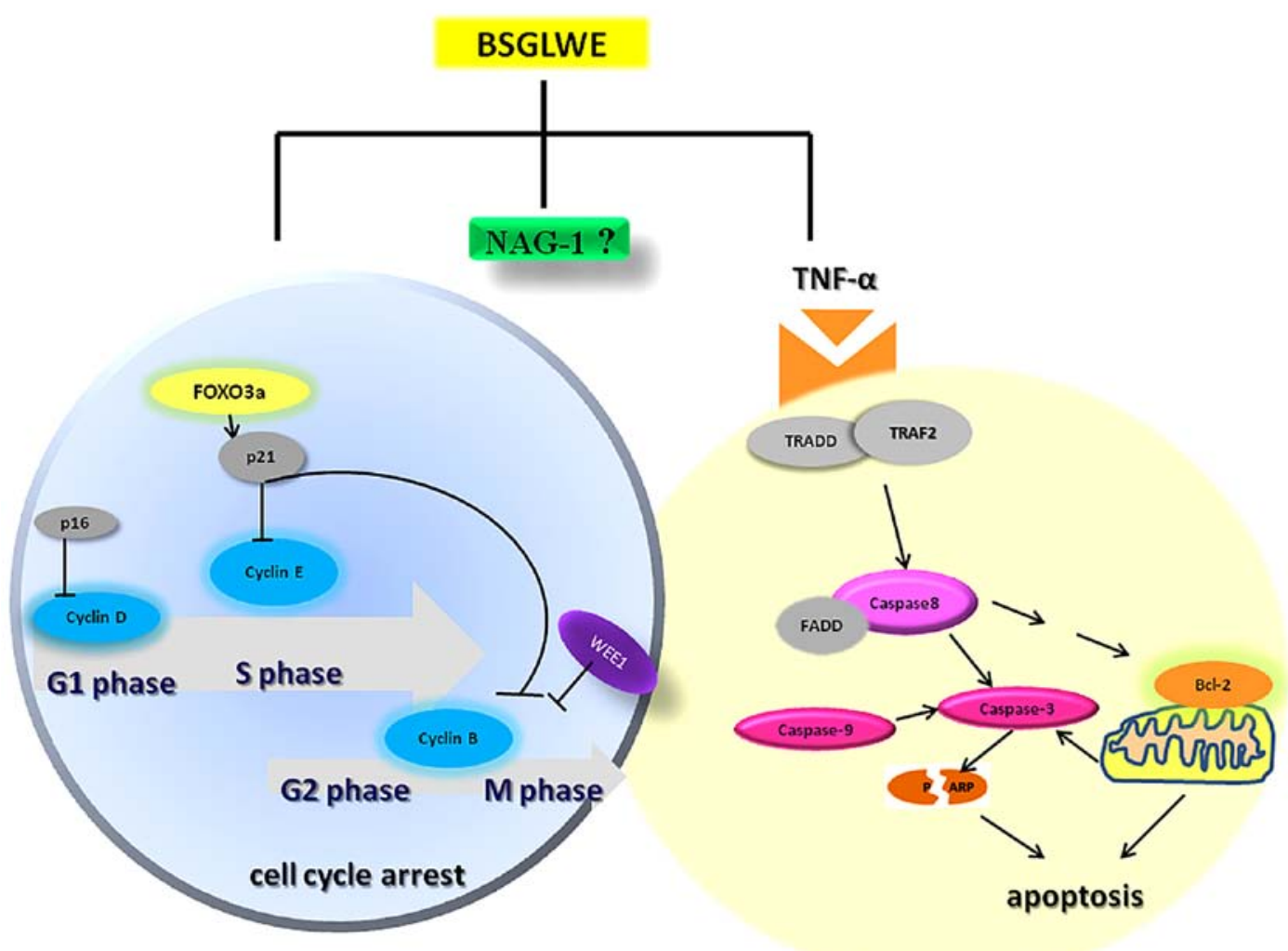

Figure 7. Working model of molecular mechanisms by which BSGLWE exerts its anticancer activity in colorectal cancer HCT116 cells and xenograft tumors. The induction of NAG-1 by BSGLWE may play a role in BSGLWE-induced cell cycle arrest and apoptosis in colorectal cancer.

thus specifically inhibit CDK4 or CDK6 activity, eventually leading to cell cycle arrest at G1 phase $(49,50)$. WEE1 is a key gene for $\mathrm{G} 2 / \mathrm{M}$ phase arrest, inhibition or downregulation of WEE1 kinase could lead to mitotic catastrophe in glioblastoma cancer cells $(31,32)$. E2F transcription factor and Rb gene family play an important role in regulating cell cycle progression from the G1 phase to the $\mathrm{S}$ phase (51). These results suggest that BSGLWE may cause cell cycle arrest at different check points in HCT116 xenograft tumors.
GLP has also been reported to induce apoptosis in several cancer cells $(13,18)$. Apoptosis is regulated by a number of genes and is a precise process. In our study, BSGLWE downregulated the expression of Bcl-2, a key anti-apoptosis molecule, both in HCT116 cells and xenograft tumors as determined by western blotting, qRT-PCR and immunostaining. The poly(ADP-ribose) polymerase (PARP), an apoptosis marker, was cleaved both in HCT116 cells and xenograft tumors upon BSGLWE treatment. The transcription factors, Forkhead box O (FOXO) genes, are 
involved in multiple signaling pathways and play critical roles in a number of physiological and pathological processes, including cancer (52). One family member, FOXO3a, has been well defined to be involved in cell cycle arrest and apoptosis induction, and FOXO3a induction is important for tumor suppression (53). In our study, BSGLWE treatment significantly increased FOXO3a expression both at mRNA and total protein levels in xenograft tumors, suggesting FOXO3a may be a potential molecular target of BSGLWE. Study by Dey et al demonstrated that both upregulation of mRNA and total protein levels of FOXO3a, but not the phosphorylated form, play a key role in 3 $\beta$-Adiolinduced apoptosis in prostate cancer cells (54). As mentioned earlier, transcription factor NF- $\kappa \mathrm{B}$ and cytokine TNF- $\alpha$ both play a key role in cellular processes including inflammation, apoptosis and cell cycle arrest.

Several studies have demonstrated that there is a signaling interplay between FOXO3a, TNF- $\alpha$, and $\mathrm{NF}-\kappa \mathrm{B}$ in regulating physiological and pathological diseases (55-57). For example, Lee et al found that FOXO3a promoted remarkable apoptosis in human endothelial cells (HUVECs) through upregulating of TNF- $\alpha$ and suppression of NF- $\kappa \mathrm{B}$ (58). Correlating with these observations, we found BSGLWE also increased TNF- $\alpha$ expression and decreased $N F-\kappa B$ expression in xenograft tumors, suggesting that the FOXO3a-TNF- $\alpha-N F-\kappa B$ network may also be important molecular targets for BSGLWE induced apoptosis and cell cycle arrest in colorectal cancer. However, apoptosis is a complex biological process which can be divided into two paths: the extrinsic and the intrinsic pathways, function via mitochondrial and death receptor, respectively (59). In this study, we found that BSGLWE also induced FADD, TRAF2, and caspase- 8 expression, key regulators of death-receptor-induced apoptosis pathway, suggesting a more complex regulation of apoptosis by BSGLWE during colorectal cancer carcinogenesis. More studies are needed to further differentiate the two pathways and the exact regulating mechanisms elicited by BSGLWE.

In the xenograft tumor study, we found both high and low doses of BSGLWE treatment significantly reduced xenograft tumor size and tumor weights compared to control group. At 0-4 weeks, the difference of tumor size was not quite obvious between treatment and control group. However, the growth rate of tumors in BSGLWE groups, especially the $300 \mathrm{mg} / \mathrm{kg}$ group, was significantly slowed down at the fifth week until end of the study. These results suggest that BSGLWE may be more effective in inhibiting colorectal tumor progression at late stage but not being quite effective in inhibiting the initiation and early development of colorectal cancer in this study. This observation may also suggest a long-term treatment with BSGLWE might be necessary for colorectal cancer prevention and therapeutic purpose in clinical practices. In agreement with our study, Shi and Qing (60) found that long-term treatment with $G$. lucidum significantly reduced death rate in late phase cancer patients as compared with short-term treatment (9). Few clinical studies in general suggest that G. lucidum is safe to either normal population or patients with disease $(61,62)$. However, the safety and potential toxicity of long-term use of G. lucidum for therapeutic purpose or prevention purpose need to be evaluated in future studies.

Cell death has been mainly categorized into apoptosis, autophagy and necrosis based on morphological features and biochemical characteristics. Recently, a growing number of studies indicate necroptosis, distinct from apoptosis and necrosis, as a new mechanism of cell death (63). Cells can readily switch from one form of death to another (64). In this study, we found that the xenograft tumor of mice treated with BSGLWE showed more necrosis in a dose-dependent manner than the control group as depicted in Fig. 6. Necrosis is often observed in the internal regions of tumors where nutrient and oxygen supplies are limited (65). Necrosis is considered to be a form of cell death characterized by early plasma membrane permeabilization and organelle swelling and is accompanied by a significant inflammatory response (66). Traditionally, apoptosis and autophagy were considered as the most prominent cell death or cell death-related mechanisms (67). By now, multiple other cell death modalities such as necrosis were described and necrosis is recognized to be most likely involved in the response to chemotherapeutic treatments (67). Other than inducing apoptosis or autophagy as their anticancer mechanisms, many natural compounds including genistein, curcumin and Berberine have been reported to induce necrosis in cancer cells as reviewed by Gali-Muhtasib et al (68). It is reported that approximately $90 \%$ of cancer patients die of metastasis due to the resistance of cancer cells to apoptosis inducing drugs (69). Kim et al reported that for prognosis, the higher the rate of necrosis area adjusted by tumor volume after chemotherapy the better the prediction of metastasis-free survival of localized osteosarcoma patients (70). Therefore, it is critical to discover anticancer drugs that induce alternative modes of cell death such as necrosis for cancer chemoprevention and therapy. Our results suggest that BSGLWE could induce both apoptosis and necrosis in HCT116 xenograft tumors and thus slow down the rate of tumor growth.

Body weight change is important in evaluating toxicity and side effects of a chemotherapy drug or nature product in animal studies. Our study indicates that BSGLWE had no negative effects on body weights of nude mice. During the study, tumor-bearing mice in control group began to lose weight (a hallmark of cachexia) at the fifth week and body weights of control group were lowest among all groups at the end of study. Cachexia is common in cancer patients and is characterized by weight loss due to skeletal muscle wasting and fat depletion (71). Cachexia causes weakness, immobility, low tolerance to anticancer therapy, and poor quality of life, which significantly contributes to cancer-related deaths in cancer patients (71). In contrast, the body weights of 150 and $300 \mathrm{mg} / \mathrm{kg}$ BSGLWE treated mice maintained a continuous increase of body weight throughout the whole experiment, suggesting BSGLWE may have a beneficial effect on attenuating cancer-induced cachexia in nude mice.

It is worth noting that lower dose of BSGLWE $(150 \mathrm{mg} / \mathrm{kg})$ may even have a protective effect since the body weight of this group was maintained at the highest level among all groups throughout the study. On the contrary, 5-FU, a commonly used chemotherapy agent, markedly induced weight loss and severe side effects in nude mice two weeks after injection of HCT116 cells. Therefore, we had to reduce the frequency of 5-FU administration to nude mice at week 2. Surprisingly, we found that after reducing 5-FU administration, tumor growth rate sharply accelerated at week 5 , suggesting relapse may 
occur upon reduction of 5-FU treatment. However, BSGLWE at either low or high doses did not show any of the side effects or signs of weight loss, indicating that BSGLWE might be a safer anticancer agent compared to 5-FU.

The combination of benefit without toxicity represents the desired end result in the development of effective therapeutic agents. G. lucidum has been used for thousands of years as a health promotion and treatment strategy. Other than studies from laboratories, there are also some published reports of human trials in the assessment of G. lucidum for treating several diseases, including cancer. In the process of clinical treatment of cancer, G. lucidum spore powder is combined with anticancer drugs to reduce reaction with radiotherapy and chemotherapy in patients. G. lucidum used as one of the component of a Chinese medicine herb complex which significantly improved immune function, overall health and ability to fight cancer in patients receiving chemotherapy or radiotherapy medications (72).

A recent meta-analysis which included five randomized controlled trials (RTC) with a total of 373 cancer patients showed that patients who had been given G. lucidum alongside chemo/radiotherapy were more likely to respond positively compared to chemo/radiotherapy alone (RR 1.50; $95 \%$ CI $0.90-2.51, \mathrm{P}=0.02$ ) (73). Among these five RTCs, four studies showed that patients treated with G. lucidum had relatively improved quality of life compared to controls (73). Our study also showed that BSGLWE protected tumorbearing mice from weight loss and reduced the degree of malignancy compared to 5-FU or control groups. However, evidence from well-designed human clinical trials is still scarce. In addition, one question is whether antitumor effects of G. lucidum is a direct activity or is mediated through effects on immune system modulation, which still is a key question to be addressed in future studies (19). Therefore, more clinical human trials are needed to better understand the bioactivity of G. lucidum, especially GLP from the sporoderm-broken spores. Investigation can progress in order to use G. lucidum as new nutraceutical or drug for the prevention and treatment of colorectal cancer in near future.

NAG-1, a pro-apoptotic gene, is a divergent member of TGF- $\beta$ superfamily. Many studies have shown that NAG-1 acts as a tumor suppressor protein by inhibiting tumor growth and inducing apoptosis in the early stages of cancer (24-27). NAG-1 induction may be associated with cell cycle arrest and apoptosis in a variety of cancer cells (24-27). NAG-1 is upregulated in human colorectal cancer cells by several NSAIDs, as well as by dietary compounds including resveratrol, genistein, diallyl disulfide, conjugated linoleic acid, green tea catechins, epigallocatechin-3-gallate (EGCG), indole3-carbinol, capsaicin and other anticancer agents (24). In this study, BSGLWE upregulated the expression of NAG-1 both in vitro and in vivo which have never been reported before.

In HCT116 cell culture medium, NAG-1 concentration was increased dose-dependently upon BSGLWE treatment as compared to control cells. In nude mice, the source of serum NAG-1 was derived from human HCT116 cells. We found NAG-1 protein secreted into serum of nude mice was also induced upon BSGLWE treatment. Laboratory studies overall suggest that NAG-1 has an anticancer effect in many types of cancer primarily through induction of apoptosis (24). However, clinical studies have shown that the expression of NAG-1 in cancer patient, including colon cancer, were elevated, especially positively correlated with tumor stage and grade $(24,74)$. Unfortunately, the exact role of NAG-1 during tumorigenesis in cancer patients is unknown. In agreement with results from laboratory studies, our study suggests that NAG-1 induction by BSGLWE may play a partial role in BSGLWE-induced apoptosis and cell death in colorectal cancer. However, more studies are needed to definitively determine whether the BSGLWE-induced cell death in HCT116 cells is through NAG-1 induction.

In conclusion, the present study demonstrated that BSGLWE significantly inhibited colorectal cancer cell proliferation and tumor growth through deregulating expression of the key molecules of cell cycle, apoptosis and proliferation as depicted in Fig. 7. BSGLWE induced NAG-1 expression in HCT116 cancer cells and NAG-1 induction may be closely related to reduced cell viability and increased apoptosis and possibly cell cycle arrest upon BSGLWE treatment as modeled in Fig. 7. To our knowledge this is the first study showing that BSGLWE could inhibit cell proliferation in colorectal cancer cells, which may involve NAG-1 induction. However, definitive role of NAG-1 in BSGLWE induced cytotoxicity in colorectal cancer need to be further elucidated in future studies. Our results also indicate that BSGLWE may serve as a novel anticancer agent for colorectal cancer chemoprevention and therapy.

\section{Acknowledgements}

We thank Dr Thomas Eling at National Institute of Environmental Health Sciences (NIEHS) for critical reading of this manuscript. We wish to thank Yu Huang at Zhejiang Medical University animal facility for his kind help in animal care and technique support. This study was supported by National Natural Science Foundation of China (grant no. 81473397).

\section{References}

1. Arnold M, Sierra MS, Laversanne M, Soerjomataram I, Jemal A and Bray F: Global patterns and trends in colorectal cancer incidence and mortality. Gut 66: 683-691, 2017.

2. Brenner H, Kloor M and Pox CP: Colorectal cancer. Lancet 383: 1490-1502, 2014.

3. Aisha AFA, Abu-Salah KM, Ismail Z and Majid AMSA: In vitro and in vivo anti-colon cancer effects of Garcinia mangostana xanthones extract. BMC Complement Altern Med 12: 104, 2012.

4. Saud SM, Li W, Morris NL, Matter MS, Colburn NH, Kim YS and Young MR: Resveratrol prevents tumorigenesis in mouse model of Kras activated sporadic colorectal cancer by suppressing oncogenic Kras expression. Carcinogenesis 35: 2778-2786, 2014.

5. Afrin S, Giampieri F, Gasparrini M, Forbes-Hernandez TY, Varela-López A, Quiles JL, Mezzetti B and Battino M: Chemopreventive and therapeutic effects of edible berries: a focus on colon cancer prevention and treatment. Molecules 21: 169,2016

6. Shehzad A, Wahid F and Lee YS: Curcumin in cancer chemoprevention: Molecular targets, pharmacokinetics, bioavailability, and clinical trials. Arch Pharm (Weinheim) 343: 489-499, 2010.

7. Dan X, Liu W, Wong JH and Ng TB: A ribonuclease isolated from wild Ganoderma lucidum suppressed autophagy and triggered apoptosis in colorectal cancer cells. Front Pharmacol 7: 217, 2016.

8. Bishop KS, Kao CH, Xu Y, Glucina MP, Paterson RR and Ferguson LR: From 2000 years of Ganoderma lucidum to recent developments in nutraceuticals. Phytochemistry 114: 56-65, 2015. 
9. Boh B, Berovic M, Zhang J and Zhi-Bin L: Ganoderma lucidum and its pharmaceutically active compounds. Biotechnol Annu Rev 13: 265-301, 2007.

10. Wasser SP: Reishi or Ling Zhi (Ganoderma lucidum). In: Encyclopedia of Dietary Supplements. Coates PM Blackman MR, Cragg GM, Levine M, Moss J, White JD (eds). Marcel Dekker, New York, pp603-622, 2005.

11. Li A, Shuai X, Jia Z, Li H, Liang X, Su D and Guo W: Ganoderma lucidum polysaccharide extract inhibits hepatocellular carcinoma growth by downregulating regulatory $\mathrm{T}$ cells accumulation and function by inducing microRNA-125b. J Transl Med 13: 100 2015.

12. Loganathan J, Jiang J, Smith A, Jedinak A, Thyagarajan-Sahu A, Sandusky GE, Nakshatri $\mathrm{H}$ and Sliva D: The mushroom Ganoderma lucidum suppresses breast-to-lung cancer metastasis through the inhibition of pro-invasive genes. Int J Oncol 44: 2009-2015, 2014

13. Shang D, Li Y, Wang C, Wang X, Yu Z and Fu X: A nove polysaccharide from Se-enriched Ganoderma lucidum induces apoptosis of human breast cancer cells. Oncol Rep 25: 267-272, 2011.

14. Yang G, Yang L, Zhuang Y, Qian X and Shen Y: Ganoderma lucidum polysaccharide exerts anti-tumor activity via MAPK pathways in HL-60 acute leukemia cells. J Recept Signal Transduct Res 36: 6-13, 2016.

15. Hsieh TC and Wu JM: Suppression of proliferation and oxidative stress by extracts of Ganoderma lucidum in the ovarian cancer cell line OVCAR-3. Int J Mol Med 28: 1065-1069, 2011

16. Cao QZ and Lin Z-B: Ganoderma lucidum polysaccharides peptide inhibits the growth of vascular endothelial cell and the induction of VEGF in human lung cancer cell. Life Sci 78: 1457-1463, 2006

17. Sun LX, Li WD, Lin ZB, Duan XS, Li XF, Yang N, Lan TF, Li M, Sun Y, Yu M, et al: Protection against lung cancer patient plasma-induced lymphocyte suppression by Ganoderma lucidum polysaccharides. Cell Physiol Biochem 33: 289-299, 2014.

18. Liang Z, Yi Y, Guo Y, Wang R, Hu Q and Xiong X: Chemical characterization and antitumor activities of polysaccharide extracted from Ganoderma lucidum. Int J Mol Sci 15: 9103-9116, 2014.

19. Ferreira IC, Heleno SA, Reis FS, Stojkovic D, Queiroz MJ, Vasconcelos MH and Sokovic M: Chemical features of Ganoderma polysaccharides with antioxidant, antitumor and antimicrobial activities. Phytochemistry 114: 38-55, 2015

20. Guo L, Xie J, Ruan Y, Zhou L, Zhu H, Yun X, Jiang Y, Lü L, Chen K, Min Z, et al: Characterization and immunostimulatory activity of a polysaccharide from the spores of Ganoderma lucidum. Int Immunopharmacol 9: 1175-1182, 2009.

21. Huang XL, Hui-Qin WU, Fang H and Lin XS: Analysis of polysaccharide from broken cellular wall and unbroken spore of Ganoderma lucidum. Chin Tradit Herbal Drugs 37: 813-816, 2006.

22. Zhao J, Qiu C, Li J, Fan J and Chen K: Inhibitive effect of seleniumenriching wall-broken Ganoderma lucidum spore powder on HepG2 cells. Life Sci 79: 1129, 2006

23. Baek SJ, Kim KS, Nixon JB, Wilson LC and Eling TE: Cyclooxygenase inhibitors regulate the expression of a TGF-beta superfamily member that has proapoptotic and antitumorigenic activities. Mol Pharmacol 59: 901-908, 2001.

24. Wang X, Baek SJ and Eling TE: The diverse roles of nonsteroidal anti-inflammatory drug activated gene (NAG-1/GDF15) in cancer. Biochem Pharmacol 85: 597-606, 2013.

25. Kang SU, Shin YS, Hwang HS, Baek SJ, Lee SH and Kim CH: Tolfenamic acid induces apoptosis and growth inhibition in head and neck cancer: Involvement of NAG-1 expression. PLoS One 7: e34988, 2012

26. Wang X, Chrysovergis K, Bienstock RJ, Shim M and Eling TE: The H6D variant of NAG-1/GDF15 inhibits prostate xenograft growth in vivo. Prostate 72: 677-689, 2012.

27. Arafat K, Iratni R, Takahashi T, Parekh K, Al Dhaheri Y, Adrian TE and Attoub S: Inhibitory effects of salinomycin on cell survival, colony growth, migration, and invasion of human non-small cell lung cancer A549 and LNM35: Involvement of NAG-1. PLoS One 8: e66931, 2013.

28. Liggett JL, Zhang X, Eling TE and Baek SJ: Anti-tumor activity of non-steroidal anti-inflammatory drugs: Cyclooxygenaseindependent targets. Cancer Lett 346: 217-224, 2014

29. Piyanuch R, Sukhthankar M, Wandee G and Baek SJ: Berberine, a natural isoquinoline alkaloid, induces NAG-1 and ATF3 expression in human colorectal cancer cells. Cancer Lett 258: 230-240, 2007.
30. Guertin AD, Martin MM, Roberts B, Hurd M, Qu X, Miselis NR, Liu Y, Li J, Feldman I, Benita Y, et al: Unique functions of CHK1 and WEE1 underlie synergistic anti-tumor activity upon pharmacologic inhibition. Cancer Cell Int 12: 45, 2012.

31. Mir SE, De Witt Hamer PC, Krawczyk PM, Balaj L, Claes A, Niers JM, Van Tilborg AA, Zwinderman AH, Geerts D, Kaspers GJ, et al: In silico analysis of kinase expression identifies WEE1 as a gatekeeper against mitotic catastrophe in glioblastoma. Cancer Cell 18: 244-257, 2010.

32. Vitale I, Galluzzi L, Castedo M and Kroemer G: Mitotic catastrophe: A mechanism for avoiding genomic instability. Nat Rev Mol Cell Biol 12: 385-392, 2011.

33. Ogawa $H$, Ishiguro $K$, Gaubatz $S$, Livingston DM and Nakatani $Y$ : A complex with chromatin modifiers that occupies E2F- and Myc-responsive genes in G0 cells. Science 296: 1132-1136, 2002.

34. Burgering BM and Medema RH: Decisions on life and death FOXO Forkhead transcription factors are in command when PKB/Akt is off duty. J Leukoc Biol 73: 689-701, 2003.

35. Li WJ, Chen Y, Nie SP, Xie MY, He M, Zhang SS and Zhu KX: Ganoderma atrum polysaccharide induces anti-tumor activity via the mitochondrial apoptotic pathway related to activation of host immune response. J Cell Biochem 112: 860-871, 2011.

36. Xu Z, Chen X, Zhong Z, Chen L and Wang Y: Ganoderma lucidum polysaccharides: Immunomodulation and potential antitumor activities. Am J Chin Med 39: 15-27, 2011.

37. Wu QP, Xie YZ, Li SZ, La Pierre DP, Deng Z, Chen Q, Li C Zhang Z, Guo J, Wong C-KA, et al: Tumour cell adhesion and integrin expression affected by Ganoderma lucidum. Enzyme Microb Technol 40: 32-41, 2006.

38. Sun Z, Huang K, Fu X, Zhou Z, Cui Y and Li H: A chemically sulfated polysaccharide derived from Ganoderma lucidum induces mitochondrial-mediated apoptosis in human osteosarcoma MG63 cells. Tumour Biol 35: 9919-9926, 2014.

39. Li WD, Zhang BD, Wei R, Liu JH and Lin ZB: Reversal effect of Ganoderma lucidum polysaccharide on multidrug resistance in K562/ADM cell line. Acta Pharmacol Sin 29: 620-627, 2008.

40. Hanahan D and Weinberg RA: Hallmarks of cancer: The next generation. Cell 144: 646-674, 2011.

41. Borgs L, Beukelaers P, Vandenbosch R, Belachew S, Nguyen L and Malgrange B: Cell 'circadian' cycle: New role for mammalian core clock genes. Cell Cycle 8: 832-837, 2009.

42. Lee B, Sandhu S and McArthur G: Cell cycle control as a promising target in melanoma. Curr Opin Oncol 27: 141-150, 2015.

43. Hochegger H, Takeda S and Hunt T: Cyclin-dependent kinases and cell-cycle transitions: Does one fit all? Nat Rev Mol Cell Biol 9: 910-916, 2008.

44. Abbas T and Dutta A: p21 in cancer: Intricate networks and multiple activities. Nat Rev Cancer 9: 400-414, 2009.

45. Lim S and Kaldis P: Cdks, cyclins and CKIs: Roles beyond cell cycle regulation. Development 140: 3079-3093, 2013.

46. Niculescu AB III, Chen X, Smeets M, Hengst L, Prives C and Reed SI: Effects of p21(Cip1/Waf1) at both the G1/S and the $\mathrm{G} 2 / \mathrm{M}$ cell cycle transitions: $\mathrm{pRb}$ is a critical determinant in blocking DNA replication and in preventing endoreduplication. Mol Cell Biol 18: 629-643, 1998.

47. Zhao S, Ye G, Fu G, Cheng JX, Yang BB and Peng C: Ganoderma lucidum exerts anti-tumor effects on ovarian cancer cells and enhances their sensitivity to cisplatin. Int J Oncol 38: 1319-1327, 2011.

48. Wang J, Zhang L, Yu Y and Cheung PC: Enhancement of antitumor activities in sulfated and carboxymethylated polysaccharides of Ganoderma lucidum. J Agric Food Chem 57: 10565-10572, 2009.

49. Soták M,Sumová A and Pácha J: Cross-talk between the circadian clock and the cell cycle in cancer. Ann Med 46: 221-232, 2014

50. Williams RT, Barnhill LM, Kuo HH, Lin WD, Batova A, Yu AL and Diccianni MB: Chimeras of p14ARF and p16: Functional hybrids with the ability to arrest growth. PLoS One 9: e88219, 2014.

51. Dyson N: The regulation of E2F by pRB-family proteins. Genes Dev 12: 2245-2262, 1998.

52. Fu Z and Tindall DJ: FOXOs, cancer and regulation of apoptosis Oncogene 27: 2312-2319, 2008.

53. Nho RS and Hergert P: FoxO3a and disease progression. World J Biol Chem 5: 346-354, 2014

54. Dey P, Ström A and Gustafsson JÅ: Estrogen receptor $\beta$ upregulates FOXO3a and causes induction of apoptosis through PUMA in prostate cancer. Oncogene 33: 4213-4225, 2014.

55. Hoesel B and Schmid JA: The complexity of NF- $\kappa B$ signaling in inflammation and cancer. Mol Cancer 12: 86, 2013. 
56. Chung HY, Lee EK, Choi YJ, Kim JM, Kim DH, Zou Y, Kim CH, Lee J, Kim HS, Kim ND, et al: Molecular inflammation as an underlying mechanism of the aging process and age-related diseases. J Dent Res 90: 830-840, 2011.

57. Fluckiger A, Dumont A, Derangère V, Rébé C, de Rosny C Causse S, Thomas C, Apetoh L, Hichami A, Ghiringhelli F, et al: Inhibition of colon cancer growth by docosahexaenoic acid involves autocrine production of TNFa. Oncogene 35: 4611-4622, 2016.

58. Lee HY, Youn SW, Kim JY, Park KW, Hwang CI, Park WY, Oh BH, Park YB, Walsh K, Seo JS, et al: FOXO3a turns the tumor necrosis factor receptor signaling towards apoptosis through reciprocal regulation of c-Jun N-terminal kinase and NF-kappaB. Arterioscler Thromb Vasc Biol 28: 112-120, 2008.

59. Dasgupta A, Nomura M, Shuck R and Yustein J: Cancer's Achilles' Heel: Apoptosis and Necroptosis to the Rescue. Int J Mol Sci 18: 1-20, 2016.

60. Shi K-G and Qing L-H: The follow-up observation assessment of medium and late phases cancer treated by Chinese Ganoderma lucidum essence (CGLE). In: Ganoderma: Genetics, Chemistry, Pharmacology and Therapeutics - Proceedings of International Symposium on Ganoderma Research 2002. http://cstm.cnki.net/stmt/TitleBrowse/KnowledgeNet/ ZGYS200210001028?db=STMI8515.

61. Zhao H, Zhang Q, Zhao L, Huang X, Wang J and Kang X: Spore powder of Ganoderma lucidum improves cancer-related fatigue in breast cancer patients undergoing endocrine therapy: A pilot clinical trial. Evid Based Complement Alternat Med 2012: 809614, 2012.

62. Suprasert P, Apichartpiyakul C, Sakonwasun C, Nitisuwanraksa P and Phuackchantuck R: Clinical characteristics of gynecologic cancer patients who respond to salvage treatment with Lingzhi. Asian Pac J Cancer Prev 15: 4193-4196, 2014.

63. Chen D, Yu J and Zhang L: Necroptosis: An alternative cell death program defending against cancer. Biochimica et Biophysica Acta 1865: 228-236, 2016.
64. Feoktistova M, Wallberg F, Tenev T, Geserick P, Leverkus M and Meier P: Techniques to distinguish apoptosis from necroptosis. Cold Spring Harb Protoc 2016: pdb.top070375, 2016.

65. Zong WX and Thompson CB: Necrotic death as a cell fate. Genes Dev 20: 1-15, 2006.

66. Kanduc D, Mittelman A, Serpico R, Sinigaglia E, Sinha AA, Natale C, Santacroce R, Di Corcia MG, Lucchese A, Dini L, et al: Cell death: Apoptosis versus necrosis (Review). Int J Oncol 21: $165-170,2002$.

67. Diederich $\mathrm{M}$ and Cerella C: Non-canonical programmed cell death mechanisms triggered by natural compounds. Semin Cancer Biol 40-41: 4-34, 2016.

68. Gali-Muhtasib H, Hmadi R, Kareh M, Tohme R and Darwiche N: Cell death mechanisms of plant-derived anticancer drugs: Beyond apoptosis. Apoptosis 20: 1531-1562, 2015.

69. Wilson TR, Johnston PG and Longley DB: Anti-apoptotic mechanisms of drug resistance in cancer. Curr Cancer Drug Targets 9: 307-319, 2009.

70. Kim MS, Lee SY, Cho WH, Song WS, Koh JS, Lee JA, Yoo JY and Jeon DG: Tumor necrosis rate adjusted by tumor volume change is a better predictor of survival of localized osteosarcoma patients. Ann Surg Oncol 15: 906-914, 2008.

71. Fearon KC, Glass DJ and Guttridge DC: Cancer cachexia: Mediators, signaling, and metabolic pathways. Cell Metab 16: 153-166, 2012.

72. Zhuang SR, Chen SL, Tsai JH, Huang CC, Wu TC, Liu WS, Tseng HC, Lee HS, Huang MC, Shane GT, et al: Effect of citronellol and the Chinese medical herb complex on cellular immunity of cancer patients receiving chemotherapy/radiotherapy. Phytother Res 23: 785-790, 2009.

73. Jin X, Ruiz Beguerie J, Sze DM and Chan GC: Ganoderma lucidum (Reishi mushroom) for cancer treatment. Cochrane Database Syst Rev 6: CD007731, 2012.

74. Khaled YS, Elkord E and Ammori BJ: Macrophage inhibitory cytokine-1: A review of its pleiotropic actions in cancer. Cancer Biomark 11: 183-190, 2012. 